\title{
Comments on applications of microcomputers in teaching
}

\author{
N. JOHN CASTELLAN, JR. \\ Indiana University, Bloomington, Indiana
}

As instructional applications of microcomputers mature, both recurrent and new themes emerge. These include (1) getting started in instructional microcomputing, (2) the identification and evaluation of software, (3) the diminishing appeal of computer-based demonstrations, (4) the increasing importance of student control in student-computer interactions, (5) the emergence of toolbased courseware, (6) the importance of thoughtful integration of computers into the course, and (7) the critical need to evaluate both course and courseware. Careful attention to these issues can improve the quality of students' understanding of psychology and the science of behavior.

The papers presented in this session point to a shift in the application of computers in teaching psychology. When microcomputers were first used in psychology courses, they usually were adjuncts to laboratory courses in cognitive and sensory psychology, in which the computers were used in laboratory work. More departments now have the resources, interest, and motivation to make use of computers in their introductory courses or the laboratories associated with these courses.

All of the papers presented in this session touch on themes that have been echoed throughout previous meetings of this Society, but new themes are emerging. For example, there has been much discussion of the types of software that can be used in the classroom or laboratory. Butler (1988) ably summarized these and identified an important trend in instructional software-the software must be a good tool for the student or instructor. The idea that software should be considered as a tool for the student to manipulate and interact with is increasingly recognized as a major factor in successful applications of computing technology to instruction (Castellan, 1987).

In discussing the use of software in the instructional laboratory, Eamon (1988) asked whether we are too concerned about the quality of the software we use. He suggested that the criteria often suggested for the selection of software concerning technical accuracy, pedagogical soundness, and substantive fidelity (see Castellan, 1986) are irrelevant, and argued that "the best software is the software that works for you." Although many would undoubtedly agree, there are problems with this notion. As Hornby and Anderson (1988) pointed out, much of the software they obtained from textbook publishers was unusable because it simply did not work properly. Although individually developed software may work well in one's own classroom, it is not easily transported to others' classes without a great deal of care and attention.

Requests for reprints should be addressed to N. John Castellan, Jr., Department of Psychology, Indiana University, Bloomington, IN 47405.
One theme made clear by all of the papers in this session is that we really do not know how to best integrate instructional computing into our classrooms. (This should not be construed as damning-even statisticians who have used computers in data analysis for 30 years cannot agree on the best way to integrate computers into statistics classes.)

\section{THEMES}

\section{Getting Started}

As computers become easier to use and software becomes more available, it is easier to get started. However, as Hornby and Anderson (1988) and Conn, Stafiniak, DiPasquale, and Harper (1988) pointed out, it still is very easy to underestimate the effort required. Not only must hardware and software be obtained, but instructors and assistants must become familiar with their use if the courseware is to be used effectively.

\section{Identifying and Evaluating Software}

Butler (1988) discussed the identification of software and software sources. As pointed out by Leith, Hamm, Duncanson, and Senical (1988) and Hornby and Anderson (1988), the identification of software is difficult: the descriptive information is sometimes misleading, the software may not work properly (or at all), and the documentation is often insufficient. There are no simple solutions to these problems. Conn et al (1988) described the situation at Drexel University: because the type of hardware selected was at that time new, it was necessary to develop the software in-house. Leith et al. (1988), at Northern Michigan University, also selected a machine for which little instructional software was available, and Hornby and Anderson (1988), at State University of New York College at Plattsburgh, found much of the existing software unsuited to their needs. At Drexel University, the administration developed a program for training and supervising students in the development of software. The organization is professional in that programmers and instructional 
designers serve as part of the development team. At Northern Michigan University, the departmental faculty developed the expertise to train and supervise students in the development of software. And at State University of New York College at Plattsburgh, rather than developing software, the decision was made to adapt suitable published materials for course use by providing special documentation for students to use.

Each of these approaches has advantages and disadvantages. Drexel University's model has the advantage of utilizing skilled people at an early stage so that (presumably) the development of materials is more efficient. On the other hand, this development requires the marshalling of many resources and may divert control away from the individual faculty member. At Northern Michigan University, the faculty retain control; however, the cost is that the faculty and students must become programmers, rather than psychologists, and the development process may be long and frustrating. Although much psychology may be learned during the development of such programs, is this an efficient use of faculty's and students' time? Is the student's priority to better learn and understand psychological concepts, or does the pressure to develop the materials compromise substantive learning? At State University of New York College at Plattsburgh, it seems that the attention is focused on the course and how to best integrate the materials. To make efficient use of the courseware, it is not necessary for students and faculty to become programmers; however, it is necessary to focus the courseware's content on the course itself. This is a good solution; it seems to me that this is what all faculty must do in relating anything to a course.

Of course, the best solution is to have good courseware available. The experiences reported by Conn et al. (1988), Leith et al. (1988), and Hornby and Anderson (1988) suggest that Eamon's (1988) rejection of standards has some dangerous pitfalls. The problems people report suggest that the published software has not been polished enough to make it generalizable for use by others. It may very well work for the developer in his or her courses, but that is not enough. We need to know how it was implemented and need documentation to facilitate its use.

How can we be sure that the materials we can obtain elsewhere are of the quality we need and deserve? One way is to look for reviews in journals such as Contemporary Psychology, Behavior Research Methods, Instruments, \& Computers, and Microcomputers in the Social Sciences. Each of these journals provides scholarly reviews of software for instructional use. In addition, we must press professional journals to do more in this areaperhaps even write letters to editors expressing our needs and concerns. Finally, and most importantly, we must press publishers to be more responsive and responsible.

There are three basic kinds of publishers of courseware. There are software publishers who publish software as their institutional goal. Such publishers know that they will succeed or fail on the quality of their materials. They know the importance of good software, and their materials usually undergo extensive review and testing before publication. Their materials are usually good. The second kind of publisher is the textbook publisher who offers courseware merely to enhance book sales. To these publishers, the important thing may be that they offer software to accompany their books; whether the software works well may be secondary. We must inform the sales representatives of these companies when their software is less than excellent. If enough faculty say that the textbook is fine but they have chosen not to adopt the text because the courseware is poor, the situation will begin to change. We must demand quality! Finally, the third type of publisher is the individual faculty member who has developed and decided to market his/her own courseware. There are many reasons for doing so-the author may simply want to make the materials available, or he/she may be an entrepreneur who wants to earn a reputation and make a bit of money, or the courseware may have been rejected for publication elsewhere. When looking at an advertising brochure, one simply cannot tell which of these possibilities motivates the author. Some courseware marketed by the author may be superb, and some may be trash.

Regardless of the source of our courseware, we must have high expectations for it. If we have little experience using courseware, how do we know what expectations we should have? In 1987, EDUCOM and the National Center for Research to Improve Post-Secondary Teaching and Learning (NCRIPTAL), in cooperation with computer manufacturers and professional associations (including the American Psychological Association), sponsored the first Higher Education Software Awards Program. ${ }^{1}$ Nearly 300 courseware packages and modules were submitted. A multitiered review was conducted, and a panel of nationally known authorities on instructional computing named the final winners. Eight packages received "best" awards, and 17 were named "distinguished." What is noteworthy is that such a small number of packages were singled out as exceptional in some way. This small body of packages can serve as a model of what is good in instructional computing and can provide useful standards for comparison.

\section{Diminishing Appeal of Demonstrations}

Many of the first courseware materials developed for use in psychology were simple demonstrations-visual illusions, conditioning of animals, repetitions of classical human learning experiments, and so forth. Although such courseware was initially met with great enthusiasm, and in spite of the fact that it has valid instructional uses, such demonstrations seem to be falling out of favor, both with instructors who have used them and with those who are investigating the possibilities of computer-based instructional materials for the first time. The problem with such software is that, even when the student serves as a subject, the activity is passive; although it increases students' understanding somewhat, it does not seem to do enough. 
Importance of Interaction and Control

What is sought increasingly by instructors is courseware that involves a great deal of interaction on the part of the student and over which the student may exert some control. For example, at Drexel University and at Northern Michigan University, the students and graduate assistants who are actively involved in development gain large amounts of knowledge and a deeper understanding of psychology through their intensive interaction with the courseware. Although they are one step removed from the students in the individual courses, they are nonetheless active participants in the learning process. The students noncomputerized courses are being encouraged to explore the phenomena under study more fully than in the typical demonstration.

\section{Demand for Tool-Based Courseware}

The concern for greater interaction and control leads to a demand for software that not only can be used to demonstrate basic psychological phenomena, but can be used as a tool for further work. Although early typologies of instructional computing stressed the importance of tools (e.g., Castellan, 1983, 1987; Hewett, 1986), the generality of the need for tools was not fully recognized. Butler (1988) clearly outlined the need to consider the use of courseware as a tool for learning. We also see this recognized in recent courseware. For example, a recent package for the Apple (Gregory \& Poffel, 1986) is designed not only to allow the student to run himself/herself as a subject in an experiment, but to enable and encourage the student to design and run experiments of the student's own design. Interestingly, the package has the word "tool" in its title. The recent second edition of one of the most popular computer packages in cognitive psychology (Levy \& Ransdell, 1988) is distinguished from the first edition (Fischler, Griggs, Warner, Sherman, \& Levy, 1979; Levy, Fischler, \& Griggs, 1979) by the added flexibility provided to enable students to explore the subject matter more fully. Conn et al. (1988) stressed that introductory psychology students at Drexel University must design and run an experiment, and Leith et al. (1988) described a software package with which students may perform virtually any conditioning experiment with a simulated rat. Finally, two other sessions at this conference stressed the importance of the computer as a tool. The emphasis in these sessions was on research, but the potential of these experimental tools for teaching is great.

\section{Importance of Integrating Software Into the Course}

One point repeated again and again throughout this session is the importance of integrating the software into the course. Eamon (1988) argued that the ultimate criterion is whether software "works for you." What he is saying is that in order to work, the software must fit your course; that is, it must be integrated. This requirement may be the primary reason for complaints about much of the software available from other sources: It was not written to be generally useful, but was designed to work in a particular course, and courses taught by different faculty at different institutions are likely to be quite different. Leith et al. (1988) described how courseware developers worked very closely with instructors. Conn et al. (1988) gave clear examples of how the material was integrated into a course not only by modifying the courseware, but by modifying other parts of the course syllabus in order to achieve instructional goals.

\section{Evaluation of Course and Courseware}

Finally, and perhaps most importantly, the course and courseware must be evaluated if the integration of computers into a curriculum is to be successful. This can be done in many ways. Conn et al. (1988) described the thorough procedures followed at Drexel University, where all participants work to evaluate and modify the course as needed. Hornby and Anderson (1988) outlined the way in which they have monitored and evaluated the effectiveness of integrating courseware into their curriculum.

\section{SUMMARY}

Although many things reported in this session should cause us concern about the integration of computers into our classes, there have been many positive reports as well. There is no guarantee that all efforts to use computers in teaching will be successful (no one can guarantee that anything done in teaching will be universally successful), but I am confident that if we, as faculty, are willing to work to evaluate software, carefully integrate it into our courses, evaluate the outcomes, and modify the courses and courseware as a result of our evaluations, we will see a payoff in greater student understanding of and excitement about psychology and the science of behavior.

\section{REFERENCES}

BUTLER, D. L. (1988). Selection of software in the instructional laboratory. Behavior Research Methods, Instruments, \& Computers, 20 , 175-177.

Castellan, N. J., JR. (1983). Strategies for instructional computing. Behavior Research Methods \& Instrumentation, 15, 270-279.

Castellan, N. J., JR. (1986). Issues in the effective use of computers in introductory and advanced courses in psychology. Behavior Research Methods, Instruments, \& Computers, 18, 251-256.

Castellan, N. J., JR. (1987). Computers and the shape of the future: Implications for teaching and learning. Education \& Computing, 3, 39-48.

Conn, G., Stafiniak, P., DiPasquale, M. C., \& Harper, L. (1988). Effects of teaching an introductory psychology laboratory using a computerized research tool. Behavior Research Methods, Instruments, \& Computers, 20, 184-187.

EAMON, D. B. (1988). Problems with evaluation of courseware for instruction in psychology. Behavior Research Methods, Instruments, \& Computers, 20, 178-179.

Fischler, I. S., Griggs, R. A., Warner, S. A., Sherman, M. E., \& LeVY, C. M. (1979). Laboratory in cognition and perception [Student manual]. Iowa City: CONDUIT.

Gregory, R. J., \& PoFfel, S. A. (1986). START: Stimulus and response tools for experiments in memory, learning, cognition, and perception [Computer program]. lowa City: CONDUIT. 
Hewett, T. T. (1986). When every student has a computer: A new perspective on courseware and its development. Behavior Research Methods, Instruments, \& Computers, 18, 188-195.

HoRNBY, P., ANDERSON, M. (1988). Using computers in introductory psychology. Behavior Research Methods, Instruments, \& Computers, 20, 180-183.

Leith, C. R., Hamm, H. D., Duncanson, C., Senical, T. (1988). A computer-driven undergraduate laboratory curriculum and related support logistics. Behavior Research Methods, Instruments, \& Computers, 20, 188-190.

LeVY, C. M., Fischler, I. S., \& Griggs, R. A. (1979). Laboratory in cognition and perception [Computer program]. Iowa City: CONDUIT

LEVY, C. M., \& RANSDELL, S. E. (1988). Laboratory in cognition and perception (2nd ed.). [Computer program]. lowa City: CONDUIT.

\section{NOTE}

1. Information concerning the EDUCOM/NCRIPTAL Higher Education Software Awards may be obtained from EDUCOM Software Initiative, P. O. Box 364, Princeton, NJ 08540. 